\title{
MOTIVASI BELAJAR BAHASA ARAB (STUDI KASUS MAHASISWA PBA IAIN PALANGKA RAYA 2017/2018)
}

\author{
Nur Fuadi Rahman \\ fuadyrahman03@gmail.com
}

IAIN Palangka Raya

\begin{abstract}
There are two types of motivations in learning second language; integrative motivation and instrumental motivation. Integrative motivation require of positiveness from students to native speaker and culture. Instrumental motivation is a feeling of language learner that they need to learn second language to get something important in their lives. In the 2017/2018 IAIN Palangka Raya had 928 students, and only 24 students choose PBA as program study. This was attracts researcher to see the motivation of PBA students in learning Arabic language from the perspective of Gardner's motivational theory. Researcher was also looking for the factors that affect the motivational. This research was use qualitative method and case study was chosen. The results showed that $42 \%$ students had integrative motivational in learned Arabic language, and the rest had 58\% of instrument motivational. One of the influence factors was student's educational background.

Keywords: Arabic language, Gardner, Instrumental motivation, Integrative motivation
\end{abstract}

\section{PENDAHULUAN}

Motivasi merupakan salah satu faktor yang harus diperhatikan dalam proses pembelajaran. Secara leksikal motivasi (motivation) berasal dari kata movere yang berarti 'to move' (bergerak). Jadi dapat disimpulkan bahwa motivasi adalah apa yang menggerakkan seseorang untuk melakukan sesuatu, berusaha dan terlibat dalam suatu kegiatan. ${ }^{1}$ Motivasi mengacu pada "alasan terjadinya sesuatu" ${ }^{2}$ Motivasi juga

${ }^{1}$ Zoltan Dörnyei dan Ema Ushioda, Teaching and Researching Motivation (Harlow: Pearson Education Limited, 2011) hlm. 3.

${ }^{2}$ Frederic Guay, Chanal, J., Catherine F. Ratelle, C. F., Marsh, H. W., Larose, S., \& Boivin, M. (2010). "Intrinsic, identified, and controlled types of motivation for school subjects digambarkan sebagai kekuatan pendorong yang memberikan energi dalam mencapai sesuatu yang diinginkan. ${ }^{3}$

Motivasi merupakan sesuatu yang sangat penting untuk siswa dalam mempelajari bahasa arab, menurut pakar motivasi dalam belajar sangatlah penting, karena motivasi akan sangat berpengaruh kedalam hasil belajar. Hal ini didasarkan kepada beberapa penelitian yang mengkaitkan motivasi dan hasil belajar bahasa arab. karena rendahnya motivasi

in young elementary school children." British Journal of Educational Psychology, 80 (4), hlm. 711-735.

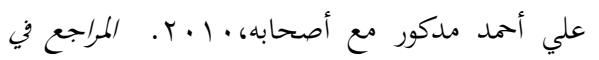

مناهج تعليم اللغة العربية للناطقين بلغات أخرى، القاهرة : دار

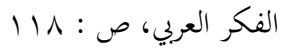


merupakan salah satu tantangan dalam pembelajaran bahasa arab.

Motivasi memiliki kontribusi besar dalam memumbuhkan minat pembelajar. Sama halnya dalam pembelajaran bahasa, motivasi memiliki peranan yang penting. Penelitian tentang motivasi pembelajaran bahasa asing tertuju pada apa yang menjadikan seseorang ingin mempelajari bahasa asing dan apa yang menjaganya agar senantiasa termotivasi untuk belajar bahasa asing tersebut. Peranan motivasi dalam mempelajari suatu bahasa asing merupakan masalah yang sangat kompleks, karena pada dasarnya bahasa selalu terkolerasi dengan konteks sosial dan budaya.

Dörnyei dan Otto mendefinisikan motivasi sebagai sejumlah faktor pendorong yang dinamis dalam diri seseorang yang menginisiasi, mengarahkan, mengkoordinasikan, menguatkan, menegaskan, dan mengevaluasi proses kognitif dan motorik saat keinginan dan harapan dipilih, diprioritaskan, dioperasionalisasikan dan diaktualisasikan, baik berhasil maupun tidak. $^{4}$

${ }^{4}$ Zoltan Dörnyei dan Ema Ushioda, Teaching and Researching Motivation (Harlow: Pearson Education Limited, 2011), hlm. 6
Motivasi dalam konteks pemerolehan bahasa kedua (asing) terbagi kedalam dua kategori, yaitu motivasi integratif dan motivasi intrumental. Motivasi integratif mensyaratkan sikap positif dari siswa terhadap penutur bahasa sasaran dan budayanya. Adapun motivasi intrumental, yaitu perasaan pembelajar bahasa mereka perlu belajar bahasa sasaran untuk mendapatkan sesuatu yang penting untuk kehidupannya, seperti pendidikan yang baik, atau pekerjaan yang bisa menjamin masa depannya. ${ }^{5}$

Dari perspektif teoritis, Fakhrurrozi menyebutkan bahwa paling tidak ada dua problem yang sedang dan akan terus dihadapi dalam pembelajaran bahasa Arab, yaitu problem kebahasaan dan problem nonkebahasaan. Lebih lanjut Fakhrurrozi menjelaskan bahwa yang dimaksud dengan problem nonkebahasaan yaitu persoalan-persoalan yang tidak terkait langsung dengan bahasa yang dipelajari oleh siswa, namun ikut berperan dalam mempengaruhi tingkat kesuksesan dan kegagalan dari pembelajaran bahasa. ${ }^{6}$ Diantara problem

5 Nasser Oroujlou dan Majid Vahedi, Motivation, attitude, and language learnin, Procedia - Social and Behavioral Sciences 29 (2011) International Conference on Education and Educational Psychology, hlm. 4

6 Aziz Fahrurrozi, Pembelajaran Bahasa Arab : Problematika Dan Solusinya, Arabiyât : Jurnal Pendidikan Bahasa Arab dan 
nonkebahasaan

dalam

pembelajaranbahasa adalah masalah yang terkait dengan faktor psikologi seperti motivasi (dawafi') dan minat (muyul) belajar. $^{7}$

Di Palangka Raya, motivasi belajar bahasa arab masih sangat rendah. Salah satu penyebabnya adalah perbedaan orientasi terhadap bahasa arab itu sendiri. Di Palangka Raya sendiri bahasa arab hanya diajarkan di sekolah dibawah kementrian agama (MI,MTS,MA,PTAI) dan pesantren-pesantren. Hal ini berbeda dengan kota lain yang mana bahasa arab diajarkan di lembaga-lembaga umum, seperti SD,SMP,SMA, PTA. Salah satu SMA di kota Malang, bahasa arab dipelajari, meskipun bukan menjadi mata pelajaran wajib. ${ }^{8}$ Bahasa Arab pun menjadi pilihan jurusan diberbagai PTN, seperti Universitas Negeri Malang, Universitas Negeri Semarang, Universitas Pendidikan Bandung, dan Universitas Gajah Mada.

Di IAIN Palangka Raya, yang merupakan satu-satunya Universitas Islam negeri yang ada di Kalimantan Tengah,

Kebahasaaraban, Vol. I, No. 2, Desember 2014 , hlm. 162

${ }^{7}$ Asep Muhammad Saeful Islam, Faktor Demotivasi Pembelajaran Bahasa Arab Dalam Perspektif Siswa Madrasah, Arabiyât : Jurnal Pendidikan Bahasa Arab dan Kebahasaaraban, 2, (1), 2015. Hlm. 2 bahasa arab merupakan mata kuliah wajib untuk semua jurusan, dan di IAIN Palangka Raya memiliki prodi Pendidikan bahasa arab. Dan didapati bahwa motivasi belajar bahasa arab masih sangat tendah, hal ini dilihat dari jumah mahasiswa yang memilih jurusan bahasa arab dari tahun ketahun maksimal hanya satu kelas yang terdiri tidak lebih dari 20 mahasiswa pada setiap tahunnya, bahkan pada tahun ajaran 2017/2018 yang mana mahasiswa baru yang masuk sebanyak 928 mahasiswa, yang memilih jurusan pendidikan bahasa arab di IAIN hanya 24 mahasiswa. ${ }^{9}$ Masih bisa dikatakan kalah pamor dengan jurusan pendidikan bahasa Inggris.

Hal inilah yang membuat peneliti tertarik untuk mengetahu apa sebenarnya motivasi dari mahasiswa PBA 2017/2018 dalam belajar bahasa arab, serta faktor yang mempengaruh motivasi mereka tersebut.

\section{LANDASAN TEORI}

\section{Motivasi Belajar Bahasa Asing}

Salah satu kajian psikologi dalam pembelajaran bahasa asing adalah motivasi. Gardner menyatakan bahwa motivasi memegang peranan yang penting dalam proses pembelajaran

${ }^{8}$ Wawancara dengan guru bahasa Arab SMA 1 Malang 
bahasa kedua. ${ }^{1}$ Dörnyei, sebagaiman yang telah dikutip oleh Khodady dan Khajavy, menyebutkan bahwa motivasi merupakan sebuah daya utama untuk menginisiasi pembelajar bahasa asing dan kemudian menjadi sebuah kekuatan pendorong untuk bertahan pada saat proses pembelajaran bahasa sering kali membuat siswa merasa bosan. ${ }^{1}$

Dari perspektif psikologi sosial, motivasi merupakan salah satu faktor utama dalam pembelajaran bahasa dan merupakan kunci sukses untuk meningkatkan intensitas belajar dan memilih strategi belajar. Penelitian tentang motivasi pembelajaran bahasa asing tertuju pada apa yang menjadikan seseorang ingin mempelajari bahasa asing dan apa yang menjaga dia untuk senantiasa termotivasi untuk mempelajari bahasa asings tersebut. Meski demikian, motivasi dalam mempelajari bahasa asing merupakan masalah yang sangat kompleks, mengingat bahasa selalu terikat konteks sosial dan budaya. Dan lebih spesifik 2017/2018

${ }^{9}$ Data Prodi PBA IAIN Palangka Raya

${ }^{1}$ Robert C. Gardner, Motlvation and Second Language Acquisition, Porta Linguarum 8 (2007), hlm. 20.

1 Ebrahim Khodady dan Gholam Hassan Khajavy, Exploring the Role of Anxiety and Motivation in Foreign Language Achievement: A lagi, penguasaan bahasa asing juga merupakan peristiwa sosial yang selalu diiringi oleh unsur-unsur kebudayaan dari bahasa asing itu sendiri. ${ }^{1}$

Terkait pembelajaran bahasa asing, motivasi mempunyai dua fungsi, yaitu fungsi integratif dan fungsi instrumental. Fungsi integratif dimaknai sebagai ${ }^{1}$ motivasi yang mendorong seseorang untuk mempelajari suatu bahasa karena adanya keinginan untuk berkomunikasi dengan masyarakat penutur bahasa itu atau menjadi anggota masyarakat bahasa tersebut. Sementara itu, motivasi menjadi berfungsi instrumental ketika seseorang memiliki kemauan untuk mempelajari bahasa kedua karena tujuan yang bermanfaat atau karena ingin mendapatkan suatu pekerjaan atau status sosial pada strata atas masyarakatnya. ${ }^{1}$

\section{Teori Motivasi Gardner}

Kajian tentang motivasi dalam konteks pembelajaran dan pemerolehan bahasa kedua atau asing cukup lama didominasi oleh teori gardner yang melihat motivasi dari dua ketegori, yaitu

Structural Equation Modeling Approach, PortaLinguarum 20 (2013), hlm. 269-286.

${ }^{1}$ Jenni Muhonen, Second ${ }^{2}$ Language Demotivation: Factors That Discourage Pupils From Learning The English Language ( Tesis di University Of Jyväskylä, 2004), hlm. 5.

${ }^{1}$ Abdul Chaer, Psikolinguistik: Kajian Teoretik (Jakarta: Rineka Cipta, 2009) hlm., 251. 
motivasi integratif dan motivas instrumental. Motivasi integratif mensyaratkan sikap positif dari siswa terhadap penutur bahasa sasaran dan budayanya. Adapun motivasi instrumental, yaitu perasaan pembelajar bahasa bahwa mereka perlu belajar bahasa sasaran untuk mendapatkan sesuatu yang penting untuk kehidupannya seperti pendidikan yang baik atau pekerjaan yang bisa menjamin masa depannya.

Salah satu temuan penting dari penelitian gardner adalah bahwa motivasi integratif memiliki pengaruh yang besar dalam pemerolehan bahasa. Semakin tinggi kadar motivasi seseorang semakin baik pula penguasaan bahasa asingnya. Selain itu, siswa dengan motivasi integratif menunjukkan penguasaan bahasa yang lebih baik dibandingkan yang bermotivasi instrumental. Siswa yang bermotivasi integratif cenderung menunjukkan sikap dan perilaku yang positif dan kondusif mereka biasanya lebih aktif dikelas, lebih antusias, suka bekerja keras, tidak mudah menyerah, dan tidak akan berhenti berusaha untuk menguasai bahasa asing tersebut. Sebaliknya siswa yang bermotivasi instrumental memperlihatkan ciri-ciri yang kurang mendukung proses belajar bahasa.
Mereka memandang bahasa asing semata-mata hanya sebagai alat untuk memenuhi kebutuhan yang bersifat praktis, misalnya untuk memperoleh pekerjaan yang baik, bukan sebagai sarana untuk mendekatkan diri kepada budaya bangsa lain. Oleh sebab itu Mereka cenderung untuk belajar secukupnya setelah kebutuhannya terpenuhi, minat atau Semangat belajarnya menjadi Pudar. Karena tidak mendorong untuk terus meningkatkan diri, penguasaan bahasanya menjadi sangat terbatas. ${ }^{1}$

Motivasi Belajar Bahasa Arab Di Indonesia

Sudah menjadi rahasia umum bahwa motivasi belajar bahasa Arab di Indonesia masih rendah, bila dibandingkan dengan bahasa Inggris. Hal ini terbukti dari sekolah-sekolah yang ada mata pelajaran bahasa Arab yang diajarkan disekolah sekolah, baik SD/MI，SMP/MTs， SMA/MA. Tidak semua sekolah yang berbasih umum (SD,SMP,SMA) menjadikan bahasa Arab sebagai mata pelajaran atau sebagai pelajaran tambahan bagi siswanya, namun sebaliknya mata pelajaran bahasa Inggris diajarkan

1 Gardner R.C., W Lambert. 1972. Attitude and Motivation on Second Language Learning. MA : Newbury House, h. 132 
sebagai mata pelajaran wajib baik di sekolah yang berbasis umum maupun berbasis Islam. Perbedaan motivasi adalah salah satu factor penyebabnya.

Hal ini didasari oleh beberapa penelitian terdahulu yang membahas motivasi belajar bahasa Arab. Dalam pidato pengukuhan guru besarnya, Ainin menyebutkan bahwa dalam konteks realitas pembelajaran bahasa Arab di Indonesia, belakangan ini disinyalir sedang terjadi fenomena demotivasi dalam pembelajaran bahasa Arab pada jenjang pendidikan dasar dan menengah, terutama di Madrasah Ibtidaiyah (MI), Tsanawiyah (MTs), dan Madrasah Aliyah (MA). ${ }^{1}$

Ainin menyebutkan fenomena lain demotivasi yang tercermin dari hasil survei terbatas pada MTs dan MA Negeri dan swasta di Kota Malang. Hasil survei terbatas yang dilaksanakan pada pertengahan tahun 2010 menunjukkan bahwa bahasa asing yang menjadi pilihan utama adalah bahasa Inggris (79\%), bahasa Arab (20\%) dan bahasa Jepang (1\%). Alasan pemilihan

${ }^{1}$ Moch. Ainin, Fenomena ${ }^{5}$ Demotivasi dalam Pembelajaran Bahasa Arab di Madrasah: Penyebab dan Alternatif Pemecahannya, pidato pengukuhan guru besar sebagai Guru Besar dalam bidang Pembelajaran Bahasa Arab pada Fakultas Sastra (FS) Universitas Malang (UM), Kamis, 28 April 2011,hlm, 3. bahasa Inggris sebagai pilihan utama lebih bersifat instrumental, yakni untuk bekerja, studi lanjut, dan karena bahasa Inggris merupakan salah satu mata pelajaran yang di-UN-kan. Sementara itu, alasan pemilihan bahasa Arab lebih dekat sebagai motivasi integratif, yakni untuk melanjutkan studi bahasa Arab ke perguruan tinggi dan bahasa Arab sebagai bahasa agama, dan sebagai alat untuk memahami agama Islam. ${ }^{1}$

Dari hasil penelitian diatas, dapat diambil kesimpulan bahwa motivasi siswa yang duduk di bangku MTs, dan MA masih sangat rendah apabila dibandingkan dengan bahasa Inggris. Dan Perbedaan motivasi menjadi salah satu faktor yang mempengaruhinya, dimana siswa yang memilih bahasa Inggris lebih condrong memiliki motivasi instrumental sebagai motivasi mereka dalam belajar bahasa tersebut, sedangkan siswa yang memilih bahasa arab lebih condrong memiliki motivasi integratif.

\section{METODE PENELITIAN}

Metode yang digunakan dalam penelitian ini adalah metode kualitatif interaktif. Studi kasus dipilih sebagai jenis dari metode kualitatif interaktif ini.Tujuan dari metode kualitatif ini 
adalah untuk menemukan informasi deskriptif tentang motivasi dalam belajar bahasa arab

Sumber data primer bagi penelitian ini adalah seluruh mahasiswa PBA IAIN Palangka Raya 2017/2018 yang berjumlah 24 orang.

Teknik pengumpulan data yang akan digunakan untuk penelitian ini adalah dengan menggunakan kuesioner terbuka yang merupakan esai singkat serta wawancara. Pengisian esai ini dilakukan dengan cara meminta siswa menuliskan catatan singkat mengani motivasi mahasiwa dalam belajar bahahsa arab serta alasan memilih prodi PBA.

Dalam penelitian ini, data yang diperoleh dari hasil esai singkat dianalisis dan disajikan dalam bentuk uraian. Kemudian dari hasil esai singkat ini, penulis mentabulasikan pernyataanpernyataan yang dikemukakan oleh mahasiswa partisipan kemudia dianalisis berdasarkan konten dari pernyataan tersebut. Hasil tabulasi ini kemudian dianalisis berdasarkan macam-macam motivasi mahasiswa dalam belajar bahasa Arab.

Selanjutnya, data hasil tabulasi tersebut dikategorikan berdasarkan frekuensi pernyataan yang dikemukakan sehingga menghasilkan gambaran umum motivasi belajar bahasa asing menurut Gardner, selanjutnya penulis mencoba untuk menganalis faktor penyebab dari motivasi tersebut dari pernyataan partisipan dilihat dari latar belakang pendidikan mereka. Dan demikian juga dengan hasil wawancara, data dikontekstualisasikan dalam macammacam motivasi dalam belajar bahasa asing menurut Gardner.

\section{HASIL DAN PEMBAHASAN}

\section{Motivasi Integratif Dalam Belajar}

\section{Bahasa Arab}

Menurut Gardner motivasi dalam belajar bahasa asing terbagi kedalam dua bagian, motivasi integratif, dan motivasi instrumental. Motivasi Integratif yaitu Motivasi integratif mensyaratkan sikap positif dari siswa terhadap penutur bahasa sasaran dan budayanya. Adapun motivasi instrumental, yaitu perasaan pembelajar bahasa bahwa mereka perlu belajar bahasa sasaran untuk mendapatkan sesuatu yang penting untuk kehidupannya seperti pendidikan yang baik atau pekerjaan yang bisa menjamin masa depannya.

Bahasa arab erat kaitannya dengan budaya bangsa arab dan ditakdirkan sebagai bahasanya Agama Islam, karena

${ }^{1}$ Ainin, Fenomena Demotivas? ..., 3 
semua ajaran islam terhimpun dalam alQur'an dan dilengkapi dengan penjelasan Hadis. Untuk dapat mengkaji dan mendalami ajaran islam, harus mempelajari al-Qur'an dan Hadis, serta kitab-kitab klasik yang menjadi sumber rujukan dalam ajaran agama Islam. Agar dapat mempelajari al-Qur'an dan Hadis dibutuhkan kemampuan berbahasa Arab yang memadai. ${ }^{1}$

Salah satu alasan mengapa alQuran itu menggunakan media bahasa Arab adalah keistimewaan linguistic bahasa itu sendiri, tidak dapat dipungkiri bahwa bahasa Arab memiliki keistimewaan linguistic dibandingkan bahasa-bahasa yang lain.

Dari Esai singkat tentang motivasi dalam belajar bahasa arab yang dikemukakan oleh para mahasiswa yang diteliti ditemukan yang memilih motivasi integratif dalam motivasi belajar bahasa arab sebesar $42 \%$ dari total respon yang berhasil dihimpun dan ditabulasi, diantara pernyataan partisipan yang menguatkan bahwa mereka memiliki motivasi integratif dalam belajar bahasa Arab antara lain sebagai berikut "bahasa Arab adalah bahasa Agama islam, karena itu saya rasa motivasi paling penting

1 Nandang Sarip Hidayat, Pिroblematika Pembelajaran Bahasa Arab, Jurnal Pemikiran Islam; Vol. 37, No. 1 Januari-Juni 2012. hlm. 84 dalam mempelajari bahasa Arab adalah Agama Islam itu sendiri, dengan mempelajari bahasa Arab akan lebih mudah memahami al-Quran dan Hadis yang menjadi sumber ajaran agama Islam".

Ungkapan senada bisa ditemukan dalam pernyataan lainnya, misal seperti pernyataan dari salah satu mahasiswa " Bahasa Arab sangat penting dipelajari karena memiliki keindahan lingusticnya dibandingkan dengan bahasa yang lain, dan menurut saya bahasa Arab lebih mudah dipelajari dari pada bahasa Inggris".

Dari mahasiswa yang memiliki motivasi integratif tersebut, 21\% cendrung memiliki motivasi agama, kemudian sebesar 16\% menjawab bahwa motivasi dalam belajar bahasa arab adalah karena keindahan linguisticnya, dan $4 \%$ sisanya menjawab " ingin lebih bisa berkomunikasi serta memahami budaya bangsa Arab". Dapat disimpulkan dari data yang telah diperoleh, bahwa motivasi integratif mahasiswa dalam belajar bahasa arab terbagi menjadi tiga ketegori, yang pertama yaitu kategori agama, yang mana motivasi agama menjadi paling banyak responden yang memilih sebagai motivasi mereka dalam belajar bahasa arab, kategori kedua, yaitu motivasi yang 
berhubungan dengan linguistic bahasa arab, serta ketegori yang terakhir, adalah motivasi yang berhubungan dengan budaya bangsa arab. ${ }^{1}$

\section{Motivasi Instrumental Dalam Belajar Bahasa Arab}

Seperti yang telah dikemukakan diatas, motivati Instrumental dalam mempelajari bahasa asing lebih condrong kepada bahasa asing sebagai alat untuk mencapai sebuah tujuan, seperti mendapat pekerjaan yang lebih baik, melanjutkan studi keluar negeri, atau hanya untuk membaca buku-buku yang menggunakan bahasa asing tersebut. Ketika siswa sudah mendapatkan sesuatu yang diinginkan, maka siswa tersebut akan berhenti belajar bahasa arab, itulah salah satu kekurangan dari motivasi ini.

Dari esai singkat yang dikemukakan mahasiswa ditemukan dalam belajar bahasa Arab. Dan terbagi kedalam empat kategori. Kategori yang paling banyak dipilih oleh mahasiswa adalah motivasi yang berhubungan dengan pekerjaan, dan yang memilih motivasi pekerjaan sebagai motivasi mereka dalam belajar bahasa Arab sebanyak $33 \%$ dari total respon yang

\footnotetext{
${ }^{1}$ Lihat tabel kuesioner
} bahwa 58\% memiliki motivasi integratif

telah dihimpun dan ditabulasi. Diantara pernyataan partisipan yang menguatkan bahwa mereka mempunyai motivasi 8 intrumental yang spesifiknya berhubungan dengan pekerjaan antara lain sebagai beriku " Guru bahasa Arab di Kalimantan Tengah masih sangat sedikit, jadi saya memilih PBA dan belajar bahasa Arab, agar bisa menjadi guru bahasa Arab dikampung halaman saya”. Ungkapan senada bisa dilihat dari peryataan yang lain yang dikemukakan oleh seorang mahasiswa, yaitu " saya memilih jurusan PBA dan belajar bahasa Arab karena saran dari guru-guru saya di SMA/MA, beliau mengatakan bahwa ditempat saya tidak ada guru bahasa Arab".

Dari data yang telah didapatkan, dapat peneliti simpulkan, bahwa peluang menjadi guru bahasa Arab di kalimantan tengah khususnya masih sangat banyak, hal ini didasari oleh penyataan mahasiswa bahwa guru bahasa Arab di kampung halamananya masih sangat sedikit, atau bahkan tidak ada.

Kategori kedua, yaitu motivasi yang berhubungan dengan studi keluar negeri. Pernyataan dari responden untuk menguatkan motivasi ini antara lain sebagai berikut " saya ingin melanjutkan studi keluar negeri, khususnya timur tengah, oleh karena itu saya semangat 
dalam belajar bahasa Arab". Dan yang memilih motivasi studi keluar negeri sebanyak $13 \%$.

Sedangkan kategori ketiga, yaitu motivasi belajar bahasa arab untuk bisa membaca kitab-kitab klasik yang berbahasa Arab. Sebanyak 8\% mahasiswa yang memilih motivasi mereka dalam belajar bahasa Arab. Penyataan mereka yang menguatkan data tersebut antara lain " saya belajar bahasa Arab agar bisa membaca kitab-kitab klasik atau kitab kuning, yang mana kitab-kitab tersebut menjadi referensi yang saya harus kuasai". Sedangkan kategori terakhir, yaitu motivasi traveling ke negara timur tengah, dan hanya $4 \%$ yang memilih motivasi ini dalam belajar bahasa arab, yang mana merupakan bagian dari motivasi instrumental dalam belajar bahasa asing. ${ }^{1}$

Faktor Yang Mempengaruhi Motivasi Mahasiswa

Untuk kategori motivasi intergratif, memang jawaban mengenai bahasa Arab sebagai bahasa Agama menjadi jawaban yang paling banyak dipilih oleh responden, atau sebanyak $21 \%$. Hal ini dikuatkan oleh pendapat Muhammad

${ }^{1}$ Lihat analisis esai singkat partisipan
Abdurrauf dan Fathi Ali Yunus dalam bukunya yang menyebutkan bahwa urgensi mempelajari bahasa Arab tidak hanya semata-mata bersifat ekonomi, budaya dan sejarah, namun yang terpenting adalah terkait dengan masalah agama. $^{2}$

Peneliti menemukan faktor yang mempengaruhi motivasi atau latar belakang mahasiswa tersebut. Responden yang memiliki motivasi integratif sebagai motivasi mereka dalam belajar bahasa arab, adalah mahasiswa yang memiliki latar belakang pendidikan atau alumni pondok pesantren yang mana belajar bahasa arab lebih intensif dibandingkan di mardarsah. Dan peneliti juga dapati lama mahasiswa yang memiliki motivasi ini dalam belajar bahasa arab di Pondoknya sekitar 6-7 tahun.

Peneliti juga menemukan bahwa responden yang memilih motivasi intrumental sebagai motivasi mereka dalam belajar bahasa arab, adalah mahasiswa yang memiliki latar belakang pendidikan yang beragam, ada mahasiswa pernah belajar di pondok pesantren baik di tingkat Tsanawiyah atau tingkat Aliyah, yang artinya mereka

2 Abdurrahman, 0 Bahasa Arab:Keistimewaan, Urgensi Dan Hukum Mempelajarinya, Jurnal Albayan : 2016, hlm. 9 
pernah belajar di pondok pesantren, dan hanya belajar bahasa arab secara intensif sekitar 3-4 tahun, dan sisa 3 tahunnya dihabisan di sekolah madrasah, baik tingkat menengah atau tingkat atas (MTs/MA). Dan bahkan ada sebagian mahasiswa yang tidak pernah belajar di pondok pesantren, yang artinya mereka hanya belajar bahasa Arab di MTs/MA saja. Hal ini kontras dengan mereka yang memiliki motivasi integratif, yang mana mereka belajar bahasa Arab lebih lama dan lebih intensif, sekitar 6-7 tahun di pondok pesantern.

Dari 24 pernyataan esai yang dapat dianalisis, motivasi intrumental dipilih oleh mahasiswa sebanyak 52\%, dan motivasi integratif dipilih $42 \%$. Dari data tersebut, sebagaimana data yang dianalisis diatas, yang peneliti lihat dari latar belakang pendidikan, bahwa $41 \%$ mahasiswa memiliki background pendidikan pernah duduk dan belajar bahasa Arab di pondok pesantren dalam kurun waktu 3-4 tahun, yang artinya mereka sekolah di madrasah setingkat SMP/MTs dan SMA/MA sebelum mereka belajar bahasa Arab secara intensif di pondok pesantren, Dan 17\% mahasiswa tidak pernah duduk dibangku pondok pesantren, atau lulusan dari MTS/MA. ${ }^{2}$

Jadi peneliti dapat simpulkan mahasiswa yang memiliki motivasi integratif adalah mahasiswa yang telah 6-7 tahun belajar bahasa arab di pondok pesantren (setingkat SMP/MTs dan SMA/MA). Dari $42 \%$ partisipan atau mahasiswa yang memiliki motivasi integratif, berlatar belakang pendidikan pondok pesanter yang mana lama mereka studi sekitar 6-7 tahun. Peniliti menarik kesimpulan, bahwa mahasiswa yang yang lama belajar bahasa arab di Pondok pesantren, sekitar 6-7 tahun akan memiliki motivasi integratif dalam belajar bahasa Arab, karena mereka melihat bahasa Arab bukan sebagai alat, namun sebagai bagian dari dirinya yang tidak dapat dipisahkan, dan melihat bahasa arab dari sudut pandang yang lain.

Meraka yang memiliki motivasi instrumental adalah mahasiswa yang latar belakang pendidikannya beragam, pernah belajar di pondok pesantren baik di tingkat Tsanawiyah atau tingkat Aliyah, yang artinya mereka pernah belajar di pondok pesantren, dan hanya belajar bahasa arab secara intensif sekitar 3-4 tahun, dan sisa 3 tahunnya dihabisan

${ }^{2}$ Lihat latar belakang pendidikan partisipan 
di sekolah madrasah, baik tingkat menengah atau tingkat atas (MTs/MA). Bahkan ada mahasiswa yang belajar bahasa Arab hanya di MTs dan MA, sehingga peneliti dapat menyimpulkan bahwa mahasiswa yang pernah duduk di bangku sekolah MTs/MA, akan memiliki motivasi instrumental.

Dari data yang telah dipaparkan peneliti, dapat ditarik kesimpulan bahwa latar belakang pendidikan merupakan faktor yang mempengaruhi motivasi dalam belajar bahasa asing, khususnya disini konteksnya adalah bahasa Arab.

\section{SIMPULAN DAN SARAN}

Dari Paparan mengenai motivasi belajar bahasa arab, yang dilihat dari teorinya Gardner baik motivasi integratif dan motivasi intrumental dalam belajar bahasa Asing, didapati bahwa 42\% mahasiswa PBA IAIN Palangka Raya memiliki motivasi integratif dalam belajar bahasa arab. Serta sisanya 58\% memiliki motivasi instrumental.

Faktor yang mempengaruhi para mahasiswa yang memiliki motivasi integratif dan motivasi interumental salah satunya adalah latar belakang pendidikan. Mereka yang memiliki motivasi integratif memiliki latar belakang pendididikan pondok pesantren, dan lama mereka studi di pondok pesantren 6-7 tahun. Yang artinya mereka memandang bahasa Arab bukan sebagaia alat, namun belajar bahasa Arab adalah sebuah kewajiban.

Sedangkan yang memiliki motivasi intrumental, adalah mereka yang pernah duduk di bangku madrasah, baik setingkat MTS/MA, dalam artian mereka studi di pondok pesantern hanya 3-4 tahun, atau dengan kata lain, mahasiswa yang pernah duduk dibangku MTs/Ma. Bahasa Arab menurut mereka adalah sebuah alat untuk meraih apa yang mereka inginkan, jadi bahasa Arab sangat penting untuk dipelajari, agar keinginan mereka dapat terwujud. Dapat dilihat pula latar belakang pendidikan akan membua siswa memiliki sudut pandang tertentu terhadap bahasa Arab.

Selanjutnya diperlukan penelitian lebih lanjut untuk mengetahui pengaruh motivasi integratif dan motivasi intrumental terhadap hasil belajar bahasa arab mahasiswa. Menurut Gardner, seseorang yang memiliki motivasi integratif akan lebih berhasil dalam belajar bahasa asing dibanding mereka yang memiliki motivasi intrumental. Karena masih sedikit sekali penelitian tentang motivasi belajar bahasa Arab. 
LAMPIRAN

ANALISIS ESEI SINGKAT

PARTISIPAN

\begin{tabular}{|l|c|c|}
\hline Motivasi Intrumental & $\mathbf{5 8 \%}$ & $\mathbf{1 4}$ \\
\hline $\begin{array}{l}\text { Mendapatkan kerja yang } \\
\text { lebih bagus }\end{array}$ & $33 \%$ & 8 \\
\hline $\begin{array}{l}\text { Melanjutkan studi ke luar } \\
\text { negeri }\end{array}$ & $13 \%$ & 3 \\
\hline $\begin{array}{l}\text { membaca kitab-kitab klasik } \\
\text { yang berbasa arab }\end{array}$ & $8 \%$ & 2 \\
\hline $\begin{array}{l}\text { mempermudah ketika } \\
\text { traveling ke jazirah arab }\end{array}$ & $4 \%$ & 1 \\
\hline $\begin{array}{l}\text { Motivasi Integratif } \\
\text { Bahasa arab adalah bahasa } \\
\text { agama Islam, sebuah } \\
\text { kewajiban untuk } \\
\text { mempelajarinya }\end{array}$ & $21 \%$ & 5 \\
\hline $\begin{array}{l}\text { Keindahan linguistic bahasa } \\
\text { arab }\end{array}$ & $16 \%$ & 4 \\
\hline $\begin{array}{l}\text { Mempelajari budaya bangsa } \\
\text { arab }\end{array}$ & $4 \%$ & 1 \\
\hline Total & $\mathbf{4 2 \%}$ \\
\hline
\end{tabular}

LATAR BELAKANG PENDIDIKAN PARTISIPAN

\begin{tabular}{|c|c|c|c|c|c|c|c|}
\hline \multicolumn{2}{|c|}{$\begin{array}{c}\text { MTS- } \\
\text { MA }\end{array}$} & \multicolumn{2}{|c|}{$\begin{array}{c}\text { Pondok } \\
\text { Pesantern- } \\
\text { MA }\end{array}$} & \multicolumn{2}{|c|}{$\begin{array}{c}\text { MTS- } \\
\text { Pondok } \\
\text { Pesantren }\end{array}$} & \multicolumn{2}{|c|}{$\begin{array}{c}\text { Pondok } \\
\text { Pesantren }\end{array}$} \\
\hline $16,5 \%$ & 4 & $16,5 \%$ & 4 & $25 \%$ & 6 & $42 \%$ & 10 \\
\hline Total & & & & 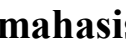 & & & \\
\hline
\end{tabular}

DAFTAR PUSTAKA

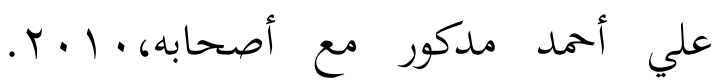
المراجع في مناهج تعليم اللغة العربية للناطقين بلغات أخرى، القاهرة : دار الفكر العربي.

Abdul Chaer. 2009. Psikolinguistik: Kajian Teoretik . Jakarta: Rineka Cipta.

Abdurrahman. 2016. Bahasa Arab:Keistimewaan, Urgensi Dan Hukum Mempelajarinya, Jurnal Albayan.

Ahmad Fuad Effendy. 2009. Metodologi Pembelajaran Bahasa Arab. Malang: Misykat.

Asep Muhammad Saeful Islam. 2015. Faktor Demotivasi Pembelajaran Bahasa Arab Dalam Perspektif Siswa Madrasah, Arabiyât : Jurnal Pendidikan Bahasa Arab dan Kebahasaaraban, 2, (1).

Azhar Arsyad. 2010. Bahasa Arab dan Metode Pengajarannya, Beberapa Pokok Pikiran. Cet III. Yogyakarta : Pustaka Pelajar.

Aziz Fahrurrozi, 2014. Pembelajaran Bahasa Arab : Problematika Dan Solusinya, Arabiyât : Jurnal Pendidikan Bahasa Arab dan Kebahasaaraban, Vol. I, No. 2, Desember.

Aziz Fakhrurrozi dan Mahyudin. 2012. Pembelajaran Bahasa Arab, Jakarta: Direktorat Jenderal Pendidikan Islam Kementerian Agama.

Ebrahim Khodady dan Gholam Hassan Khajavy. 2013. Exploring the Role of Anxiety and Motivation in Foreign Language Achievement: A Structural Equation Modeling Approach, Porta Linguarum.

Jenni Muhonen, 2004. Second Language

Demotivation: Factors That

Discourage Pupils From

MOTIVASI BELAJAR BAHASA ARAB (STUDI KASUS MAHASISWA PBA IAIN 
Learning The English Language ( Tesis di University Of Jyväskylä).

Moch. Ainin. 2011. Fenomena

Demotivasi dalam Pembelajaran

Bahasa Arab di Madrasah:

Penyebab dan Alternatif

Pemecahannya, pidato

pengukuhan guru besar sebagai

Guru Besar dalam bidang

Pembelajaran Bahasa Arab pada

Fakultas Sastra (FS) Universitas

Malang (UM).

Nandang Sarip Hidayat. 2012.

Problematika Pembelajaran

Bahasa Arab, Jurnal Pemikiran

Islam; Vol. 37, No. 1 JanuariJuni.

Nasser Oroujlou dan Majid Vahedi, Motivation, attitude, and language learnin, International Conference on Education and Educational Psychology. Procedia - Social and Behavioral Sciences 29, 2011.

Peter MacIntyre. 1994. Toward a social psychological model of strategy use" Foreign Language Annals.

Robert C. Gardner. 2008. Motivation and Second Language Acquisition, Porta Linguarum.

Snow, Catherin E 1986. "Billingual and Secobd Language Acquistition Psycholinguistic. Ed. Jean Berco Gleason and Nan Bernstein Ratner. USA : HBC Publiser,

Zoltan Dörnyei dan Ema Ushioda, Teaching and Researching Motivation Harlow: Pearson Education Limited, 2011. 